\title{
Study on the Salt Resistance of the Sprout of Fraxinus velutina
}

\author{
Jing Shu, Jinqiang $\mathrm{Xu}$
}

Shandong Agriculture and Engineering University, Ji'nan, 250100, China

\author{
Keywords: Fraxinus velutina, Sprout, Salt resistance, Research
}

\begin{abstract}
Recent years, with the constant development of social economy and industry estates, the increasing deterioration of natural environment leads to the deterioration of the plants growth environment, which influenced the good and fast growth of plants. Environmental stimulus might lead to the generation of plant stress factors, among which, the salinization is the most important stress factor for plant growth at present. Therefore, this paper mainly takes the seed and sprout of fraxinus velutina as study object, through seed germination experiment and sprout planting experiment to research the growth and physiological changes of fraxinus velutina in the alkali soils to realize the study on the salt resistance of sprouts.
\end{abstract}

\section{Introduction}

Alkali soil is one kind of the saline lands, currently, the soil salinization has already seriously threatens plant growth and the soil resource balance, and the area of salinization land is increasing. At present, there are also many researches on the soil salinization and its development and utilization in China. With the unceasing development of biological technology, our country's application and research for salinization land and plants also achieved significant progress, constantly increase of the variety of salinization plants has an important meaning for the research that plant growth adapt to the environment.

\section{Materials and methods}

\section{Experimental materials}

Landscape architecture practice base selected from Shandong Institute of Agricultural Engineering, one thousand seeds with weight of $2312 \pm 0.13 \mathrm{~g}$, no bad seeds, full grain, embryo developed completely; all the sprouts grow strongly, no violation of disease and pests, grow evenly.

\section{Experimental design}

Treatments in this experiment are mixed with a certain ration of sodium chloride( $\mathrm{NaCl})$, sodium sulfate $\left(\mathrm{Na}_{2} \mathrm{SO}_{4}\right)$, sodium bicarbonate $\left(\mathrm{NaHCO}_{3}\right)$, sodium carbonate $\left(\mathrm{Na}_{2} \mathrm{CO}_{3}\right)$ according to different features of the components and saline and alkaline of the inland saline-alkali land of our country, labeled with A、B、C、D、E according to the increasing sequences, each treatment is set with 50、100、200、300 $\mathrm{mmol} \cdot \mathrm{L}^{-1}$ concentration treatment, represented by $1 、 2 、 3 、 4$ respectively.

This experiment is mainly divided into seed experiment and sprout experiment, seed experiment is to make germination experiment operation for different alkaline salt concentration, later measure indicator at fixed period, each treatment use the way of 4 treatments according to different concentration, and set the control group $\mathrm{F}$ as the neutral salt stress, concentration should be the same with the above; make different concentration operation first for the sprout experiment ${ }^{[1]}$, them measure the indicators, each treatment use the way of 4 treatments, set neutral salt stress separately, concentration should be the same with the above. 


\section{Experimental treatment}

\section{Seed experiment}

Steep the fraxinus velutina seed in the water with temperature of $45^{\circ} \mathrm{C}$, everyday change water once, put it into the germination box after 21 days, choose 50 seeds after treating and arranged into 4 groups, 4 repeats, then put sponge and filter paper in the germination box as seedbed, treat the filter paper according to different alkaline salt solutions, then put seeds on the seedbed with light to make it sprout, sprout temperature should kept at $25^{\circ} \mathrm{C}$, and weigh it daily and add water for the sprout.

Sprout experiment

Group the chose sprouts, transplant the sprouts in the planting basin evenly, regroup sprouts after 49 days, chose the well-growth sprouts and divide into 24 groups randomly, one is control group, one is treatment group[2], make alkaline salinity-alkalinity stress treatment for the 18th group, neutral salt treatment for the 4th group, 4 repeats, 3 basins each group.

Make stress treatment after 30 days, irrigate 3 times with 3L solution in corresponding concentration for every basin, make every sprout be stressed completely, later put a plastic basin with $2 \mathrm{~L}$ salt solution under the basin, then record the specific place of the solution in the basin, and check the solution content in the basin everyday, add supplement for the decreased solution, take rain-proof measures, stay for 10 days.

\section{Experimental method}

Measure for the germination percent

Since the day putting seeds on the seedbed, observe the growth of seeds, and inspect relevant content according to the national standard for germination rate, growth trend and germination vigor, statistical calculating the germination trend after 1 week, calculate germination rate 2 weeks later, germination vigor index=germination rate * seeding fresh weight.

Measure sprout height

Measure the sprout height with regular measurement on the $1^{\text {st }}, 10^{\text {th }}, 20^{\text {th }}, 30^{\text {th }}$ stress day, record the present height in detail.

Measure the protective enzyme activity

Enzyme solution acquisition: take fresh leaf $0.5 \mathrm{~g}$ add $1 \mathrm{ml}$ phosphate buffer, grind the leaf and add $4 \mathrm{ml}$ buffer solution, stir evenly and put into the centrifuge tube, balance it. Temperature should be controlled $0-4^{\circ} \mathrm{C}$, store coldly after 12000 rpm20 minutes.

Measurement for superoxide dismutase (SOD)activity: the observation group should be added with $20 \mu$ l supernatant, the control group should be added with $20 \mu l$ buffer solution into 2 tubes, then respectively add $3 \mathrm{ml}$ reaction liquid into two groups, 1 tube in the control group should be keep black state[3], others should be left under the sunlight to react for about 20min, make color comparison under 560nm ; Measurement for peroxidase(POD)activity: add $20 \mu \mathrm{l}$ supernatant into the cuvettes for the observation group, add $20 \mu$ l hosphoric acid for the control group, then respectively add $3 \mathrm{ml}$ reaction liquid into two groups, make color comparison under 470nm and record the OD value of the $0 \mathrm{~min} 、 1 \mathrm{~min} 、 2 \mathrm{~min}$; Measurement for catalase(CAT): add $30 \mu \mathrm{l}$ supernatant into the cuvettes for the observation group, add $30 \mu \mathrm{l}$ hosphoric acid for the control group, then respectively add $3 \mathrm{ml}$ reaction liquid into two groups, make color comparison under $240 \mathrm{~nm}$ and record the OD value of the 0min. $1 \mathrm{~min}$.

Measurement for osmoregulation substance

Proline(Pro) content: take 0.5 fresh sample and add $5 \mathrm{ml}$ sulphosalicylic acid, then seal it and heat with boiling water for 10min, then store for cooling, after completely cooled, filter it with filter paper, then absorb $2 \mathrm{ml}$ filtered liquid, take $2 \mathrm{ml}$ steamed water for the control group, respectively add $2 \mathrm{ml}$ glacial acetic acid for two groups, then add $3 \mathrm{ml}$ acid hydrate indene three ketone color liquid, heat with boiling water for $40 \mathrm{~min}$, add $5 \mathrm{ml}$ methylbenzene after cooling, shake it, take $520 \mathrm{~nm}$ supernatant for color comparison.

Soluble sugar content: take 0.5 fresh samples and add with $10 \mathrm{ml}$ steamed water, then seal it and heat with boiling water for 30min (shake 1 time in the middle), then store for cooling, after 
completely cooled, filter it with filter paper, store it in the $50 \mathrm{ml}$ volumetric flask, clean the residues and test the capacity. Then absorb $1 \mathrm{ml}$ extracted liquid, add ml steamed water in the observation group, add $2 \mathrm{ml}$ steamed water in the control group. Then add $0.5 \mathrm{ml}$ anthrone fluid of ethyl acetate, then add $5 \mathrm{ml}$ concentrated sulphuric acid, shake and heat with boiling water for $1 \mathrm{~min}$, stay for cooling, take 630nm for color comparison.

Soluble protein content: take fresh leaf $0.5 \mathrm{~g}$ add $1 \mathrm{ml}$ phosphate buffer, grind the leaf and add $4 \mathrm{ml}$ buffer solution, stir evenly and put into the centrifuge tube, balance it. Temperature should be controlled $0-4{ }^{\circ} \mathrm{C}$, centrifuge for $20 \mathrm{~min}$, then stay for cooling. Add $20 \mu \mathrm{l}$ supernatant for the observation group, add $20 \mu \mathrm{l}$ water for the control group, add $3 \mathrm{ml}$ coomassie Brilliant Blue for both groups, stay for $2 \mathrm{~min}$, take 595 for color comparison.

Measure for biomass

After sprouts being treated according to different methods mentioned above, wash the soil in the basin, then dry the surplus moisture on the sprout, weigh and pack for the root, stem and juice of the fresh sprouts, them bake it under temperature of $105^{\circ} \mathrm{C}$, then lower the temperature to $70-80^{\circ} \mathrm{C}$ after 25.3h then bake for one day, then take out and weigh.

Data processing

Data of this experiment will be processed with SPSS11.5, EXCEL2000.

\section{Result analysis}

\section{Analysis of stress factors and stressed value}

All the ion concentration of salinity and sodion( $\mathrm{Na}+)$, chloride ion(Cl-), sulfate ion(SO42-),bicarbonate ion(HCO-3), carbanion(CO32-) can be calculated out. The $\mathrm{pH}$ value of treatment concentration can be replaced by figures, the measurement of treating liquid buffering capacity can be realized by hydrochloric titration, relevant data showed that the ion related number of different alkaline stress is different.

\section{Exploration for the germination physiology of fraxinus velutina seeds under the alkaline stress}

Analysis on the influence of neutral salt alkaline treatment on the germination rate
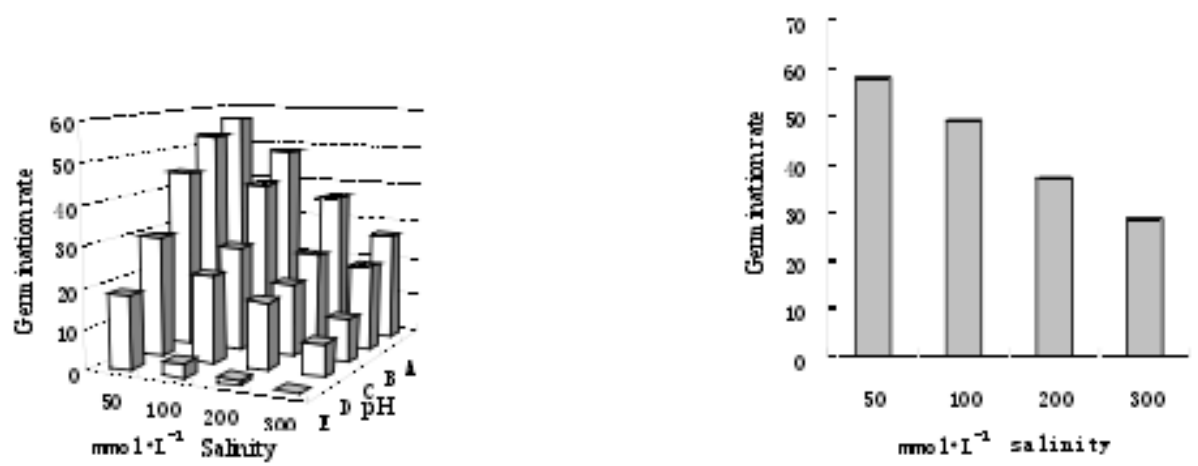

Fig. 1. Influence of alkaline stress on the germination rate Fig. 2. Influence of neutral salt alkaline stress on the germination rate

From the comparison in the pictures we know that under the situation that under the salt concentration of $50 \mathrm{mmol} \cdot \mathrm{L}-1$ and under the neutral alkaline stress and neutral salt stress, the germination rate is obviously higher than the alkaline salt stress, but the research showed that with the increase of alkaline concentration, the germination rate of fraxinus velutina is decreased gradually, with the increase of salt concentration, the alkaline concentration is compelled to decrease, thus at that time the seed germination rate is mainly influenced by the salt concentration, conversely, the alkaline concentration has some stress on the seeds[4], the stress are different for the different structure of the neutral salt stress. At the same time, the germination trend and activity are obviously higher than the alkaline salt stress, and with the unceasing increase of alkaline concentration, the germination trend 
and activity are obviously decreased, if the salt concentration and the alkaline concentration affects at the same time and the salt concentration with higher content, the germination rate, germination trend and activity are obviously lower than the pure high salinity and high alkali. Thus there is cooperativity between them.

Analysis on the influence of neutral alkaline salt treatment on the SOD、CAT of seeds

Superoxide dismutase(SOD)and catalase(CAT)can effectively control plant overoxidation and decrease membrane system damage. One of the important indicator of plant resistance is SOD value, CAT can translate the hydrogen peroxide in the SOD into water, thus can maintain the active oxygen at the lower level. This research showed that SOD activity of all groups is rising, meanwhile, under the situation of same salt concentration, it main showed the trend of rising, decreasing and rising, while the concentration trend also exist relevant difference, the main reason for this difference is influenced by the interaction functions between strong basicity and sodion. CAT shows rising tend[5] in the different salt concentration, under the situation of same salt concentration, the changes among groups are different, it shows rising under the state of $100 \mathrm{mmol} \cdot \mathrm{L}-1$, rising then decreasing under the situation of $200 、 300 \mathrm{mmol} \cdot \mathrm{L}-1$, the reason for decreasing is that the stress is beyond the bearing range of sprouts, it leads to the decrease of sprouts' enzyme activity, leads to the accumulation of active oxygen to break enzyme structure and goes into a vicious circle. Under the stress of neutral salt, the effective rise of salt concentration will make the functional enzyme increase, thus can know the influence of alkaline stress.

Influence of neutral alkaline salt treatment on the sprout growth

Sprouts will be influenced by multiple factors during the growth, the emerge and influence of environment stress factors can directly reflect the fitness degree of sprouts on the living environment, under the salt stress, the plants growth will be influenced.

The result of sprout resistance experiment showed that among the research on treatment groups, the sprout survival rate under the neutral salt stress can reach $100 \%$, while under the alkaline stress, all the sprouts in the E4 group died on the $8^{\text {th }}$ day, while the sprout survival rate of the D4 group can reach $80 \%$, the sprout survival rate of other groups can reach $100 \%$. Plant leaves are the most dynamic factor of metabolism in the plant growth. Salt marsh will lead to the unceasing accumulation of sodion and chloridion on the sprout leaves, thus to stop the transmission of nutrient to the leaves, then leads to to the inactiviation of leaves. Under the stress of neutral salt with 300 $\mathrm{mmol} \cdot \mathrm{L}^{-1}$ concentration, there are brown spots from the bottom to the top of the leaves, leaves on the bottom were withered, under the stress of alkaline, there are yellow leaves in the $4^{\text {th }}$ group on the $4^{\text {th }}$ day, and neutral salt showed no changes.

Under the stress of alkaline salt, the height and growth rate of the fraxinus velutina sprout are influenced, researches showed that with the increasing of alkaline salt and the prolong of time, the height and growth rate of sprouts showed descend, at the same time, the influence of high salt and high alkaline on the sprout height and growth rate is higher than single salt and alkaline.

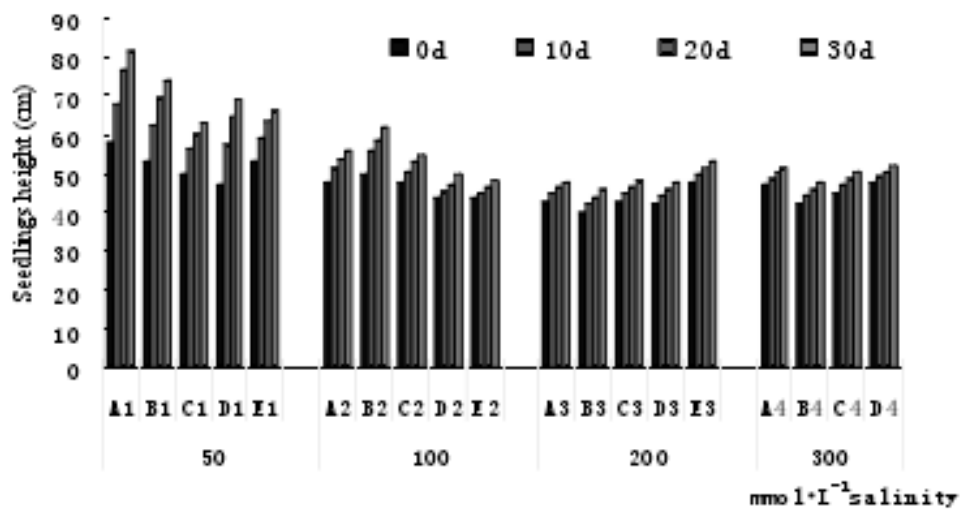

Fig. 3. Influence of alkaline stress on the height of fraxinus velutina sprouts 


\section{Conclusion}

Above all, this paper take fraxinus velutina seeds and sprouts as experimental objects, discuss the biological changes of the growth and germination under the neutral salt and alkaline salt stress, from above research we know that the neutral and alkaline salt stress can obviously restrain the germination rate and activity of the fraxinus velutina seeds, restrain the growth height and rate of sprouts, meanwhile the influence of high salt and high alkaline on the sprout height and growth rate is higher than single salt and alkaline. Thus, the research in this paper can constantly stimulate the application and research of the alkaline plants in our country, has a great meaning.

\section{Acknowledgments}

This paper belongs to Shandong Natural Fund, the fund name is Study on the Molecular Marker of the Selective Breeding of Alkali-Resisting Fraxinus Velutina , fund No.: ZR2011CQ007.

\section{References}

[1] Lini. Comparison of salt resistance of different fraxinus velutina and analysis on the 36th RAPD space mutagenesis fraxinus velutina. Gansu Agricultural University, 2013.

[2] Lv Tingliang. Study on the biological reaction of 4 species fraxinus velutina. Shandong Agricultural University, 2010.

[3] Zhaohao. Study on the biological reaction of fraxinus velutina to $\mathrm{NaCl}$ salinity. Nanjing Forestry University, 2010.

[4] Zhangjing. Study on the salt resistance and greening technology of vegetation in the heavy saline-alkaline fields of the Yellow River Delta..Chinese Marine University, 2010

[5] Du Zhenyu, Liu Fangchun, Ma Bingyao, Dong Haifeng, Ma Hailin. The root distribution and growth of the artificial mingled forest of robinia pseudoacacia and fraxinus velutina in the coastal saline area. Forest science,2014,03:10-15. 